\title{
FACULTY APPOINTMENTS IN ACTUARIAL SCIENCE \& INSURANCE
}

\author{
Nanyang Technological University, Singapore, \\ School of Accountancy and Business
}

Applications are invited for faculty positions in Actuarial Science in the School of Accountancy and Business. The School offers undergraduate degrees in Accountancy and Business, MBA degrees, and Master's and Doctoral degrees by research, and the latter by research and coursework.

Applicants should be experienced and qualified actuarial professionals with a strong interest in education, scholarship and research. Besides a professional actuarial qualification, they should also hold a postgraduate degree. In addition, they should be able to demonstrate academic and research achievement and potential.

The person appointed would be expected to teach in the B Bus' (Actuarial Science) programme as well as actuarial subjects at a postgraduate level. In particular, he/she should be able to teach the following subjects: probability and statistics, life contingencies, mathematics of finance, applied actuarial statistics, mortality investigations, social security and pension funds, actuarial management, and actuarial aspects of general insurance.

The person appointed would also be expected to contribute actively to the School's research programme, to supervise research students and to take the lead on research projects.

\section{Gross annual emoluments (for 12 months) range as follows}

\begin{tabular}{|c|c|c|}
\hline & $000-S \$ 202,110$ & er : $\mathbf{S \$}$ \\
\hline
\end{tabular}

The commencing salary will depend on the candidate's qualifications, experience and the level of appointment offered.

In addition to the above, the University may decide to pay an annual variable component/allowance which has, in the past years ranged from 1 month' to 3 months' salary.

Leave and medical benefits will be provided. Other benefits, depending on the type of contract offered, include provident fund benefits or an end-of-contract gratuity, settling-in allowance, subsidised housing, children's education allowance, passage assistance and baggage allowance for transportation of personal effects to Singapore. Staff members may undertake consultation work subject to the approval of the University, and retain consultation fees up to a maximum of $60 \%$ of their gross annual emoluments in a calendar year.

Applicants should send their detailed curriculum vitae, including their areas of research interest, publications list and the names and addresses (internet and fax, if any) of three referees to:

Director of personnel, Nanyang Technological University

Nanyang Avenue, Singapore 639798

Telefax : (65) 791340 — Internet : CCLIM@ntu.cdu.sg 